\title{
FORUM
}

\section{The McIntosh Parallel Ruler}

\author{
from Captain Brett Hilder
}

A NEw type of parallel ruler on rollers, devised and patented by $\mathrm{Mr}$. Ian $\mathrm{A}$. McIntosh of Sydney, deserves the attention of marine navigators. The new ruler is apparently similar to the brass-roller type used in the Navy, but it has the great advantage of omni-directional mobility. It also has much easier manouvrability than the parallel rules used in the Merchant Service, known as Captain Field's or the 'walk-about' type.

The new ruler is not yet in commercial production, but several models have been tried by members of the Australian Institute of Navigation, and found entirely satisfactory. The most surprising feature of the McIntosh ruler is that it moves not only at right angles to and in the direction of its length, but in any intermediate direction as well, while retaining its parallel qualities better during movement than the brass roller type used in the Navy. It is therefore possible to move it in any direction, to any corner of the chart, without it running foul of any obstructions on the chart-table.
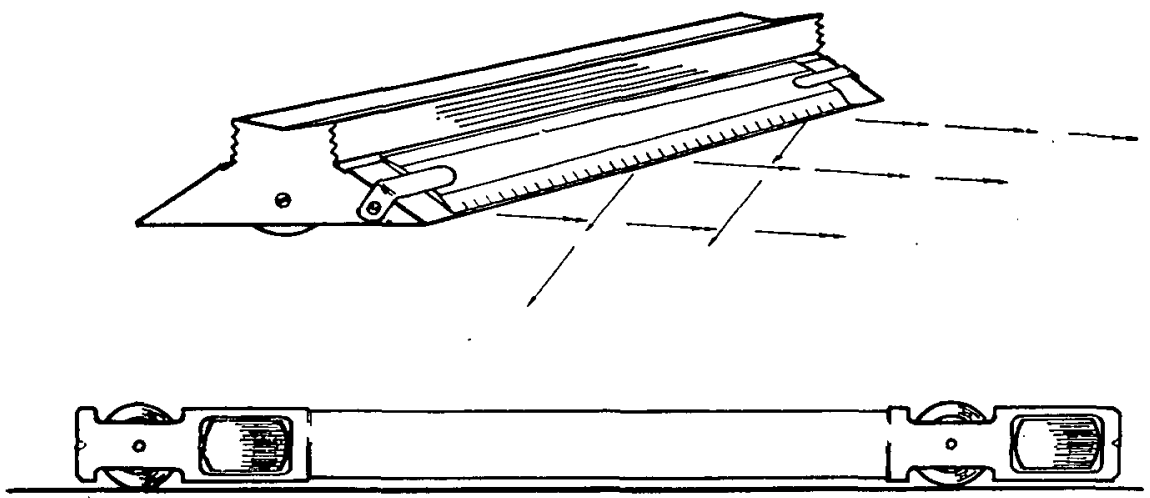

Fig. 1

The raised centre of the ruler serves as a secure handgrip, and the cavity under it houses a long tube mounted in nylon pivot bearings. The tube does not touch the chart itself, but carries four nylon rollers which have a better grip than metal, and also greater resistance to wear and damage by shock. The rollers are spherical, with their polar caps cut away as segments to allow for mounting on their axes. The rollers are set in pairs at each end of the tube, and each is at right angles to its neighbour, while they are all on axes at right angles to the tube (Fig. I). This arrangement enables the weight of the ruler to be carried on one pair at a time, though the weight can pass freely from one pair to the other as the ruler is moved broadside. When the ruler is moved in the direction of its length the weight is carried on one pair of rollers. The rollers are grooved around their equator or circumference like a motor-car tyre, the grooves being about one-sixteenth of an inch apart and less than that in depth. 
It is proposed to fit a perspex scale of degrees around the ruler, so that the chart can still be seen through it. There is also the possibility of fitting scales of distance in clips along one edge, but not for marine use.

I am assured that the moving parts and bearings, made of nylon, are selflubricating and also unlikely to wear appreciably over a period of years.

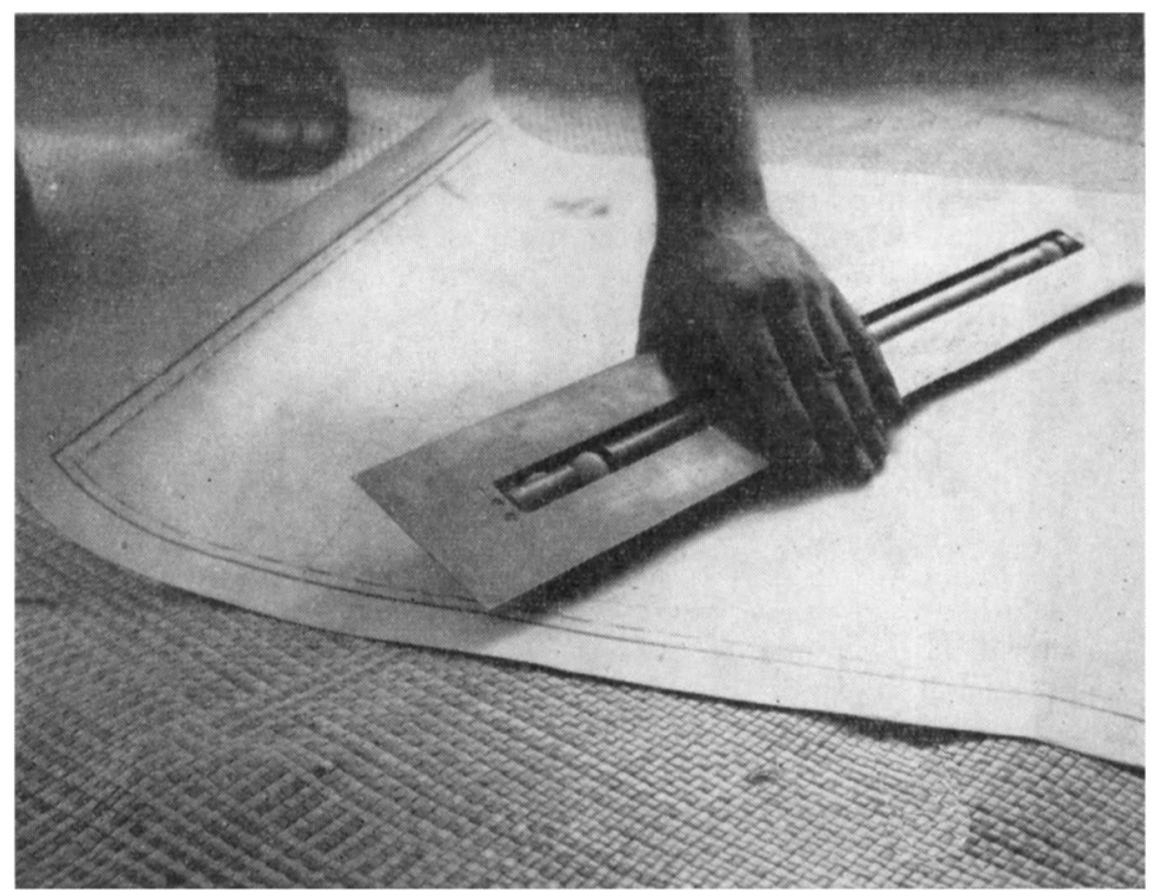

Fig. 2

In regard to the most useful length of the ruler, we come up against the fact that the size of the chart table varies in different ships and in different services. At present it is being made in three lengths, 15,18 and 21 in. The longer rulers would be best in large merchant ships, while the shorter ones would be more popular in smaller vessels, whether naval, merchant or fishing vessels.

\section{The Brest-Canaries Race}

\section{from Commander Mario Bini, Italian Navy}

IN the Brest to Las Palmas de Gran Canaria race held last August by the Sail Training Association I was skipper and navigator of the 7-ton yawl Artica II of the Italian Navy (which incidentally obtained the best corrected time of all three classes). From the navigational point of view the race offered no particular difficulty because although long- 1400 miles-we were on a reach most of the time, a condition that makes the navigator's job much easier. It might in any case 